$\xi=-1$

\title{
Recordkeeping Metadata Standardization for Electronic Health Records System Integration: a Preliminary Study
}

\author{
Seri Intan Idayu Binti Shahrul Asari, *Nurussobah Binti Hussin, Ahmad Zam Hariro Bin Samsudin and Mohd Ni- \\ zam Bin Yunus \\ ${ }^{I}$ Faculty of Information Management, Universiti Teknologi MARA, Shah Alam
*Corresponding author: * Nurussobah Binti Hussin, Ahmad Zam Hariro Bin Samsudin and Mohd Nizam Bin Yunus: Faculty of Infor-
mation Management, Universiti Teknologi MARA, Shah Alam
}

\begin{abstract}
Electronic Health Records (EHRs) are beneficial in improving patient care, promoting safe practice, as well as enhancing patients and multiple providers' communication and risk error reduction. However, it seems that the adoption of EHR system is happening very slowly to become fully integrated in both primary care and within hospital settings. In Malaysia, the implemented system still has limited integration and interoperability for supporting clinical operations among other Ministry of Health Malaysia (MOHM) hospitals, health centres, and clinics. Therefore, the objective of this paper is to discuss about this scenario and strain the need for solution through the consideration towards metadata standard establishment in health records system integration. Method used in this study is literature review analysis and face-to-face interview. The paper begins with discussions from various literatures highlighting the need of metadata standard for recordkeeping system integration. Subsequently, the face-to-face interview is done to explore the real situation in Malaysia to encounter the scenario discuss in the literatures. The finding of this study reveals that there is significant need for further research on record keeping metadata standard development for realization of electronic health records system integration. This study is significant for records managers, information technology managers, system developers and record keeping audit.
\end{abstract}

Keywords: Electronic Health Records; integration; interoperability; recordkeeping metadata

\section{Introduction}

Nowadays, the adoption of electronic health records (EHR) in medical system setting is not something new. The demand towards electronic records is said to be beneficial to the organization. According to Palabindala, Pamarthy, \& Jonnalagadda [1], EHRs are beneficial in improving patient care, promoting safe practice, as well as enhancing patients and multiple providers communication and risk error reduction. More than that physicians reported, high levels of satisfaction and confidence in the reliability of the system is by adopting EHRs. However, despite the potential advantages, it seems that the adoption of EHR system is happening very slowly to become fully integrated in both primary care and within hospital settings.

In Malaysia conversely, it was noted that the implemented system still has limited integration and interoperability for supporting clinical operations among other Ministry of Health Malaysia (MOHM) hospitals, health centres, and clinics [2]. The case put a situation where different providers and hospital having additional barriers in term of interoperability to effective data sharing. This deficiency of synchronised data management and exchange reflects that health records are fragmented, rather than cohesive [3]. The same scenario in archival records, current recordkeeping and archival standards seem to be insufficiently prescriptive to certify interoperability, and do not model all the required elements to enable discovery and access by the members of the wider community. In a smaller scale of an organisational perspective, study found structural barriers in developing interoperability initiatives for public access [4].
Standards and guideline is needed particularly to design business system as current standards in place are only focus on management operation. The non-existence of standards leads towards improper management of electronic health records as evidence (Discussion on 8 Dec 2016 and 16 Dec 2016 with Record Manager HUiTM and Secretary of general SARBICA 2013-2018; archivist NAM). This is supported by Lee, Kim, \& Kim [5] systems, such as Order Communication System (OCS), Picture Archiving and Communications System (PACS), and Electronic Medical Records (EMR), are independently operated without formal standards related to medical records management. One of the biggest challenges in the area of e-health standardization is the production of multitudinous e-health standards developed by numerous standardization bodies. Many of these are not interoperable or not directly coordinated with each other at an organizational level [6-7].

The achievement of creating systems in improving healthcare system delivery has emerged new issue in continuum care and continuous access of the medical content. The lack of standards in collecting and sharing the health information reduces efficiency and hinders collaboration as healthcare organizations expand. Current system is operating independently as it differs by variety of technology platform and sharing patients' medical records cannot be done [8-9].

\section{Objective of Study}

The objective of the study is to investigate the recent status of electronic health record system development in hospital particularly in metadata management. In order to achieve the objectives, the 
main question in the interviews are divided into several main themes which includes; (1) current status of electronic health record system development in hospitals; (2) issues regarding the management of electronic health records system in hospitals; (3) proper existing guidelines available for the integration of electronic health records system (4) suggestion for improvement (5) further research needed on recordkeeping metadata for the contribution towards integrated health records system.

\section{Literature Review}

\section{The Need of Metadata Standard for Recordkeeping Sys- tem Integration}

Metadata are the glue that binds the various components of a record together and relate the record to other records that are relevant to their understanding and use [10]. Recordkeeping metadata it not a static profile of a document or another information asset.

This is a key feature that distinguishes recordkeeping metadata from other types of metadata [11]. Record Keeping Metadata is seen to be the right solution for the integration of electronic health record where metadata is an important concept for electronic records for making records understandable and usable. It must be realized that electronic records lack certain elements of traditional records relate to the correlation between a record and its administrative and functional context. Metadata assist to map this administrative and documentary relationship within record keeping systems.

Therefore, to ensure electronic transactions and the records generated are not at risk, a recordkeeping metadata standard is required [12].

According to Hammami, Bellaaj, \& Kacem [13], inconsistent and badly documented standards are identified as the challenges that hinder the progress towards achieving truly beneficial semantic interoperability medical information systems (MISs). . This is supported by Lee, Kim, \& Kim [5], systems, such as Order Communication System (OCS), Picture Archiving Communication System (PACS), and Electronic Medical Records (EMR), are independently operated without formal standards related to medical records management. Interoperability problems often result from a lack of standards, ambiguous standards, or standards being misinterpreted [5, 14]. Moreover, there is evidence that necessities for interoperability must be designed into 'standards, processes, tools, and systems' and cannot simply or reliably be retrofitted $[4,15]$. In other word, the demand for interoperability between diverse MISs developed is truly still disgruntled13.

Bunn [16], suggested that an investigation has to be made into which 'standards' are being used, and how they are being used, within archives, records management and other related fields today [16]. . For instance, the attention would be into the relationships between standards such as ISO 23081 and guidelines such as MoReq2010, traditionally thought of as of interest to records managers, those such as Preservation Metadata: Implementation Strategies (PREMIS) which come from digital preservation, and those which are more concerned with resource discovery, such as Metadata Object Description Schema (MODS) and Dublin Core. More of such works would be beneficial in the establishment of metadata standard and guidelines fit with the system in place to expand the option of resolving the problem specifically.

Metadata provides proper data creation, storage and retrieval, modification, use, retention and destruction. Minnesota Historical Society stated that it consists of controlled vocabulary and a standardized structured format which allow for a particular description of record value, content and location [12]. Furthermore, metadata is important in business systems. In order is to capitalize on the value of your metadata, it has to be well specified and well managed, both immediately and in the long term. It should not be created on an ad hoc basis. If your agency is developing and implementing a custom-built business system, you will need to design a comprehensive recordkeeping metadata set that supports your business needs. If you are implementing an off-the-shelf software package, you will need to identify and apply a metadata schema to support recordkeeping requirements for information in that system. If your agency takes up a service offering for a system that performs or supports business processes, you will need to work with the service provider to identify key metadata that maps to your requirements. Understanding and documenting the metadata within a service offering is important to managing the records and information through transition out of the service arrangement [12].

Based on previous research the findings indicated that the experts unanimously agreed that the following elements are of great importance in the management of electronic records in organizations: Recordkeeping Metadata Requirements. The experts also agreed highly on the importance of the type of information identified in the recordkeeping metadata to be captured along with the creation of electronic records during the business activity of the organization. It is being highlighted that the record keeping metadata is important elements [12].

Standardization of data elements is very critical to ensure consistency and interoperability. The Ministry of Health Malaysia initiated the total hospital information system (THIS) as the first national electronic health record system for use in selected public hospitals across the country. The structural model output revealed that the proposed adequate infrastructure, system interoperability, security control, and system compatibility were the significant predictors, where system compatibility became the most critical characteristic to influence an individual health care provider's performance $[2,17]$.

The need for record keeping metadata standard development is crucial. All countries seem be equally advanced in information systems planning before they realize the necessity for adoption of metadata standards. Preferably, metadata standards are the first step that should be plan by the countries.

Regrettably, the significance of metadata is typically being understood after a country becomes involved with planning and information systems. The evidence of complicating use of metadata standards cause by lacking in communication between professional who develop digital information systems and those who develop the standards is often occurs which impede interoperability [18] .

\section{Results and Discussion}

In an initial exploration of the current state of Electronic Health Records in Malaysia, a preliminary study was carried out in December 2016. The following are the findings from the interviews which has been analysed by themes.

\section{Current status of Electronic Health Record System Devel- opment in hospitals}

According to first interview, hospital in Malaysia are divided three i.e. Ministry of Health Malaysia (MOHM) hospital, Private and Non-MOH hospitals. Non-MOH Hospital is divided into two which includes army hospital and university hospital. Non-MOH is semi-government hospital.

Regardless of the division, all system in hospital having issues in terms of integration because they should follow different enforcement of reporting the medical records. Both respondents given the same answers regarding the integration issues within hospital in Malaysia.

It is known that $\mathrm{MOH}$ hospital used Total Health Information System (THIS) to assist them in giving services. THIS is design by several systems that capture data such as Picture Archiving Communication System (PACS), Laboratory Information System (LIS) Electronic Medical Records (EMR) and more. The business system of hospital is residing in EMR which consist of patient data. Electronic Medical Records (EMR) consist of other system such as Medical Treatment Information System (SMRP 2.0), Patient Registry Information System (PRIS) and Case mix and more to collect data in the database. It is usually place under the management of records management department. Data are collected 
and kept in 'My Data Warehouse' for future data retrieval. This is the setting that exists in $\mathrm{MOH}$ hospital.

On the contrast, non-MOH hospital is only submitted total reporting once a year to health informatics centre (under MOHM). Meanwhile, private hospital applies different practices that used ereporting for submission to health informatics centre. This variation of practices become the challenges for integration.

Meanwhile, general standards are developed by Malaysian Administrative Modernization and Management Planning Unit (MAMPU). The Ministry of Health Malaysia (MOHM) are the organization that monitors the developments. Even though the integration within $\mathrm{MOH}$ hospital is being initiated, there is constrain especially for hospital that is not govern by Ministry of Health Malaysia (MOHM). Furthermore, according to second respondent, the initiatives by MOHM is not yet being reviewed with the general standard govern by National Archives of Malaysia (NAM).

\section{Issues regarding the management of electronic health records system in hospital}

The main issue in Electronic Medical Records (EMR) is when every hospital has different business function and they are under various authorities that govern them. Some systems in hospital are built from different vendors. Ministry of Health Malaysia (MOHM) will introduce to non-MOH hospital to uses same systems as Ministry of Health Malaysia (MOHM) hospital. However, these systems are not yet integrated within each other. Data redundancies, migration from different system becoming some of the issues arises. Some issue is occurred because of the different version of the system itself. There is also issue regarding privacy and confidentiality arises that conflicted between the ease of sharing from the integration of system. The different angle from second respondent reveal about the standard that are not yet in place. For now, the standardization of ERMS in every hospital in Malaysia is only covers the system that is used in the management area. It is said that there is not yet available the enforcement for the business system to be standardized. That is the core content of MS16175 part three is reviewed for. Part three deals with business system which in hospital involving patient medical records. In August 2016, National Archives has endorsed the circular for ERMS but that is only applied for management systems (used for administration of hospital). These issues related with timeframe of system development and development of standard in health organizations. The seven flagships of Multimedia Super corridor are seen to be the reason of tremendous number of system being build including in hospital facilities. At that point, the establishment of standard is established based on the continuously developed technology. Due to the different range of time in development between standard and system, a complete standard is not yet available for the management of business system by National Archives of Malaysia. Therefore, a research on recordkeeping metadata standard would benefit and support both the development of electronic health records system in hospital as well as the development of standard by National Archive.

\section{Proper guidelines for the integration of electronic health records system is not yet in place}

Both respondents reported that a proper guideline for the integration of electronic health records system is not yet in place. NAM has adopted MS16175 in managing records (papers and electronic) in organizations. There are three parts in the standard. Part three covers the general standard for business system. The latest progress, part three is reported to be in place but still being reviewed in terms of it applicability with Malaysian environment.

University hospital (non-MOH hospital) facing more challenges to integrate with other system. They use in-house system that they build or buy from vendors. The system would in nature have different architecture and technical features. This system is continuously being improved while it is continuously being developed. In that matter, a complete proper guideline for integration is not yet available for guidance at the moment. Furthermore, according to second respondent, government hospital in Malaysia is govern under National Archives of Malaysia must follow the complete lifecycle of records managements. So far, the general standard that covers business system in hospital that fit with National Archive regulation is not yet available. At the moments, Ministry of Health Malaysia (MOHM) are following their own initiative to improve from time to time according to the advancement of technology and clients demands. In addition, according to the second respondent, it is necessary to improve the establishment of standard that govern by National Archives of Malaysia as other highly developed countries like Australia and Korea are also in the stage of reviewing the standards for continuously improve in the future. These separated initiatives from both organization need to be synchronized to achieve one possible solutions that will initiated a complete guideline for proper management of electronic health records management in hospitals.

\section{Areas of improvement}

It is suggested that proper standard need to be developed to allow the integration of health records system in hospital. The respondent suggests that more research to be done to support phase by phase of business system that follow MS16175 part three in the future. Considering Korean experience, they have different system in each hospital. However, they manage to comply with general standards. The second respondent opinion in this matter is, the internal assessment for each organization is crucial to fit with specific preferences of organization as their function and procedures is differ from each other. This is similar with first respondent that suggest that each case need to be consider for better integration of the whole system.

To conclude, the respondents agree that further researches are needed on recordkeeping metadata for the contribution towards integrated health records system. The first respondent said that academically metadata is relevance as the solution for these issues, but practically it need to be further refined. The specific focus for metadata types that need to be integrated must be identified for further research and solutions. The key for standardization is to find uniformity in various platform. This is the point that the researcher found that metadata standardization is the key towards the uniformity of different system platform. As for second respondent, the development of general standard need continuous research as supporting evidence for better implementation of standardize electronic health records system. Therefore, further research on this matter would give benefit to the improvement of general standard that fit with National Archive regulations. Figure 1 shows the mains themes that being summarized based on the general guidelines instruments being used in both face-to-face interviews:

\begin{tabular}{|l|l|l|}
\hline \multicolumn{1}{|c|}{ Main Themes } & \multicolumn{1}{|c|}{ First respondent } & \multicolumn{1}{|c|}{ Second respondent } \\
\hline $\begin{array}{l}\text { Current practice in } \\
\text { the management of } \\
\text { health records sys- } \\
\text { tem? }\end{array}$ & $\begin{array}{l}\text { Different hospital has } \\
\text { different system even } \\
\text { though govern under } \\
\text { same authority } \\
\text { Some hospital builds } \\
\text { in-house system }\end{array}$ & $\begin{array}{l}\text { In term of standard, } \\
\text { implement theitiatively } \\
\text { continuously developed } \\
\text { Fully integrated system } \\
\text { that fit with } \\
\text { National Archive stand- } \\
\text { ard not yet being im- } \\
\text { plemented }\end{array}$ \\
\hline $\begin{array}{l}\text { Issues regarding the } \\
\text { management of } \\
\text { electronic health } \\
\text { records system in } \\
\text { general hospital? }\end{array}$ & $\begin{array}{l}\text { Integration } \\
\text { Privacy and confiden- } \\
\text { tiality }\end{array}$ & $\begin{array}{l}\text { Data redundancies } \\
\text { Sharing versus privacy } \\
\text { business system } \\
\text { General standard is still } \\
\text { being reviewed to en- } \\
\text { force standardization for } \\
\text { business system to all } \\
\text { health organization }\end{array}$ \\
\hline $\begin{array}{l}\text { Proper existing } \\
\text { guidelines for the } \\
\text { integration of elec- } \\
\text { tronic health rec- } \\
\text { ords system }\end{array}$ & $\begin{array}{l}\text { Not yet } \\
\text { Integration still is the } \\
\text { biggest issues as dif- } \\
\text { ferent hospital follow- } \\
\text { ing their own practices }\end{array}$ & $\begin{array}{l}\text { Not yet to be done phase } \\
\text { Need to bhe }\end{array}$ \\
$\begin{array}{l}\text { Fully integrated elec- } \\
\text { tronic health records } \\
\text { system that follow } \\
\text { lifecycle records govern }\end{array}$ \\
\hline
\end{tabular}




\begin{tabular}{|l|l|l|}
\hline & by National Archive is \\
\hline $\begin{array}{l}\text { Suggestion to im- } \\
\text { prove related issues } \\
\text { not yet in place }\end{array}$ & $\begin{array}{l}\text { Proper standard need } \\
\text { to be developed } \\
\text { Each case need to be } \\
\text { consider for better } \\
\text { integration }\end{array}$ & $\begin{array}{l}\text { More discussion, times } \\
\text { and cooperation within } \\
\text { countries is needed } \\
\text { Internal assessment for } \\
\text { each organization is still } \\
\text { needed to comply with } \\
\text { general standard }\end{array}$ \\
\hline $\begin{array}{l}\text { The need for } \\
\text { recordkeeping } \\
\text { metadata guideline / } \\
\text { requirement for the } \\
\text { contribution to- } \\
\begin{array}{l}\text { wards the solution } \\
\text { of integrated health } \\
\text { records system }\end{array}\end{array}$ & $\begin{array}{l}\text { In theory metadata is } \\
\text { relevance to solve the } \\
\text { problem. However, the } \\
\text { specific focus of what } \\
\text { metadata involves is } \\
\text { crucial so that it fit } \\
\text { with practical doing in } \\
\text { real environment }\end{array}$ & $\begin{array}{l}\text { Yes. It is because the } \\
\text { development of general } \\
\text { standard need continu- } \\
\text { ous research as the } \\
\text { supporting evidence for } \\
\text { better implementation of } \\
\text { standardize electronic } \\
\text { health records system }\end{array}$ \\
\hline
\end{tabular}

Fig. 1. Summary of findings

\section{Conclusion}

As for the conclusion, the need for metadata standardization is crucial. The issue is still in the spotlight that requires to be resolve for better management of Electronic Health Records (EHR). Research works is demanded to be done to explore the possible solution of these issues. More than that, on a wider view, a complex structural and procedural framework in implementing interoperability in e-health systems requires involvement of all relevant stakeholders and necessitates action at political and legal levels, as well as organizational, semantic, and technical levels.

Public education and awareness rising are also included covering action at all levels [14]. Continuous effort in research would give greater impact that will address the issue as well as the beginning of all effort to be taken. Further research on recordkeeping metadata standard development is critically demanded to find solutions in the future. This study is significant for records managers, information technology managers, system developers and record keeping audit to be aware of the arise issues.

\section{References}

[1] Palabindala, V., Pamarthy, A., \& Jonnalagadda, N. R. (2016). Adoption of electronic health records and barriers. Journal of Community Hospital Internal Medicine Perspectives, 6(5), 32643.

[2] Mohd Salleh, M. I., \& Abdullah, R. (2016). The influence of system quality characteristics on health care providers' performance: Empirical evidence from Malaysia. Journal of Infection and Public Health, 9(6), 698-707. https://doi.org/10.1016/j.jiph.2016.09.002

[3] Ekblaw, A., Azaria, A., Halamka, J. D., Lippman, A., Original, I., \& Vieira, T. (2016). A Case Study for Blockchain in Healthcare: "MedRec" prototype for electronic health records and medical research data MedRec: Using Blockchain for Medical Data Access and Permission Management.

[4] Rolan, G. (2017). Towards Archive 2.0 : issues in archival systems interoperability. Archives and Manuscripts, 43(1), 42-60. https://doi.org/10.1080/01576895.2014.959535

[5] Lee, J.-Y., Kim, Y., \& Kim, G. (2013). A Study on the Analysis and Improvement of Medical Record Management in Large University Hospitals. Korean Journal of Records Management, 13(1), 107-134.

[6] AbuKhousa, E., Mohamed, N., \& Al-Jaroodi, J. (2012). e-Health Cloud: Opportunities and Challenges. Future Internet, 4(4), 621645. https://doi.org/10.3390/fi4030621

[7] Bahga, A., \& Madisetti, V. K. (2013). A cloud-based approach for interoperable electronic health records (EHRs). IEEE Journal of Biomedical and Health Informatics, 17(5), 894-906. https://doi.org/10.1109/JBHI.2013.2257818

[8] Abd Ghani, M. K., Bali, R. K., Naguib, R. N. G., \& Marshall, I. M. (2008). Electronic health records approaches and challenges: a comparison between Malaysia and four East Asian countries. International Journal of Electronic Healthcare, 4(1), 78-104. https://doi.org/10.1504/IJEH.2008.018922

[9] Paper, C., Khanapi, M., Ghani, A., Teknikal, U., Naguib, R., \& Internat, C. (2008). Issues and Challenges in the Development of Electronic Health Records in Malaysia and VN-HISMANAG' 08 -
Conference on Applications of Medical Informatics in Hospital Management Issues and Challenges in the Development of Electronic Health Records in Mala.

[10] International Records Management Trust. (2016). Managing Metadata to Protect the Integrity of Records, (May).

[11] Department of Education LINC Tasmania. State Records Guideline No 5 Recordkeeping Metadata (2015).

[12] Aliza Ismail. (2010). Assessing the practice of trusted electronic records management in Malaysia government - controlled companies. Univerisiti Teknologi MARA, Malaysia.

[13] Hammami, R., Bellaaj, H., \& Kacem, A. H. (2014). Interoperability of healthcare information systems. The 2014 International Symposium on Networks, Computers and Communications, 1-5. https://doi.org/10.1109/SNCC.2014.6866536

[14] Kovac, M. (2014). E-health demystified: An E-government showcase. Computer, 47(10), 34-42. https://doi.org/10.1109/MC.2014.282

[15] Joanne Evans, Sue McKemmish and Barbara Reed, 'Making Metadata Matter: Outcomes from the Clever Recordkeeping Metadata Project', Archives \& Manuscripts, vol. 37, no. 1, 2009, pp 28-56.

[16] Bunn, J. (2017). The Journal of the Archives and Records Association Developing descriptive standards: a renewed call to action. Archives \& Records. Taylor \& Francis. https://doi.org/10.1080/23257962.2013.830066

[17] Health Informatics Centre. (2013). HIMS Blueprint (Vol. 13). Retrieved from http://www.moh.gov.my/images/gallery/publications/hi/HIMS Blueprint.pdf

[18] World Health Organization. (2012). Management of patient information. Global Observatory for eHelath series - Volume 6 